\title{
Effect of fructo-oligosaccharide supplementation in soya beverage on the intestinal absorption of calcium and iron in newly weaned rats
}

\author{
Maisa de Lima Correia Silva ${ }^{1}$, Patrícia da Graça Leite Speridião ${ }^{1}$, Lila Missae Oyama ${ }^{2}$ and \\ Mauro Batista de Morais* \\ ${ }^{1}$ Departamento de Pediatria, Disciplina de Gastroenterologia Pediátrica, Universidade Federal de São Paulo, \\ Rua Coronel Lisboa 826, 04020-000 São Paulo, SP, Brazil \\ ${ }^{2}$ Departamento de Fisiologia, Disciplina de Fisiologia da Nutrição, Universidade Federal de São Paulo, Rua Botucatu 862, \\ $2^{\circ}$ andar, 04023-060 São Paulo, SP, Brazil \\ (Submitted 2 May 2018 - Final revision received 3 August 2018 - Accepted 9 August 2018)
}

\begin{abstract}
Studies have shown the positive effects of prebiotics on the intestinal absorption of Ca and Fe. The present study evaluated the effect of fructooligosaccharide (FOS) supplementation in soya beverage (SB) on absorption mechanisms of Ca and Fe in recently weaned rats. Male Wistar rats were divided into four groups: lactose-free cows' milk (CM), lactose-free CM with FOS (0.8 g/100 ml) (CMF), SB and soya beverage with FOS $(0 \cdot 8 \mathrm{~g} / 100 \mathrm{ml})(\mathrm{SBF})$. These rats were euthanised after 1 week of treatment. Organ weight, $\mathrm{pH}$ of the caecal content and absorption mechanisms of $\mathrm{Ca}$ and Fe were evaluated. The results showed that the weight of the caecal contents increased in the CMF and SBF groups, and the pH of the caecal contents was lower in these groups. The Hb levels of the CMF and SB groups were higher when compared with that of the CM group and lower in relation to the SBF group. The apparent $\mathrm{Ca}$ and Fe absorption and apparent Ca retention in the CM group were higher when compared with the SB group, whereas in the CMF group, they were higher in relation to the SBF group. Divalent metal transporter 1 (DMT1) protein expression in the duodenum was higher in the SBF group than in the SB and CMF groups. SB resulted in lower intestinal Ca absorption and higher $\mathrm{Hb}$ concentration, despite the lower apparent Fe absorption in relation to CM. Supplementation with FOS provided beneficial effects on $\mathrm{Hb}$ and DMT1 protein expression in the duodenum, in addition to improving the absorption process.
\end{abstract}

Key words: Soya milk: Prebiotics: Intestinal absorption: Calcium: Iron: Rats

Currently, there are many soya beverages (SB) in the market. These beverages are based on soya extract, supplemented with or without nutrients and do not meet the recommendations of infant feeding, because of either their protein quality or mineral content, and hence cannot receive the name of infant formula $^{(1)}$.

In the beginning, the consumption of SB was limited mainly to people with lactose intolerance as a low-cost substitute for cows' milk $(\mathrm{CM})$, to vegetarians and to people with food restrictions ${ }^{(2,3)}$. However, this product is now being widely used for its good acceptance and is being consumed on a large scale, indicating that the consumers have introduced it into their eating practices ${ }^{(4)}$.

According to the studies that evaluated the knowledge of paediatricians and nutritionists regarding $\mathrm{CM}$ and its derivatives in exclusion diets, with emphasis on infant feeding, beverages or juice based on soybean extract were considered by several professionals as possible substitutes for CM protein ${ }^{(5,6)}$.
Raw soyabean has antinutritional factors in its composition that are capable of producing negative effects on human health. Among them, phytates are prominent, which can interact with minerals such as Fe and $\mathrm{Ca}$ and reduce their absorption ${ }^{(2,7,8)}$. Phytic acid has long been considered an antinutritional factor because it can form complexes with proteins and metal ions and prevent optimal absorption of minerals from the intestine ${ }^{(9)}$. In this sense, high phytate concentrations in soya-based beverages decrease the bioavailability of many minerals, including $\mathrm{Ca}$ and $\mathrm{Fe}^{(10)}$.

$\mathrm{Ca}$ and $\mathrm{Fe}$ are elements of great nutritional importance. $\mathrm{Ca}$ is the main mineral present in bone tissue, and its importance is imperative for adequate growth ${ }^{(11)}$. Similarly, Fe is also as important and is found to be lacking in Fe-deficiency anaemia, particularly during childhood; this deficiency is characterised as an important nutritional problem in this phase of life ${ }^{(12)}$. Thus, optimising the bioavailability of $\mathrm{Fe}$ and Ca present in foods is an important action

Abbreviations: 25(OH)D, 25-hydroxyvitamin D; CM, animals fed lactose-free cows' milk; CMF, animals fed lactose-free cows' milk supplemented with fructooligosaccharides; DMT1, divalent metal transporter 1; FOS, fructo-oligosaccharides; Ht, haematocrit; SB, animals fed with soya-based beverage; SBF, animals fed with soya-based beverage supplemented with fructo-oligosaccharides.

*Corresponding author: M. B. de Morais, fax +55 11 5579-5834, email mbmorais@gmail.com.br 
to prevent their deficiency. In this sense, the interactions between different nutrients in the bioavailability of $\mathrm{Fe}$ and $\mathrm{Ca}$ and other minerals have been investigated in the last few decades.

In this scenario, prebiotics have received special attention regarding the physiological aspects of $\mathrm{Ca}$ and $\mathrm{Fe}$ absorption ${ }^{(13-16)}$. Prebiotics act on the absorption of minerals, promoting the synthesis of short-chain fatty acids, generating soluble complexes and increasing surface absorption and the number of receptors and beneficial bacterial populations, among other mechanisms ${ }^{(17,18)}$. Among the prebiotics, fructo-oligosaccharides (FOS) are one of the most studied and well-established prebiotics ${ }^{(19,20)}$, and recent studies have shown their benefits associated with mineral absorption ${ }^{(17,21-23)}$ without presenting damage to the body growth of animals. However, these studies did not evaluate the effects of prebiotics added to SB when compared with $\mathrm{CM}$.

Thus the present study was performed based on the fact that there are few studies in the literature that have evaluated the absorption of $\mathrm{Ca}$ and Fe from SB compared with CM. Moreover, in general, the existing studies used a single test meal ${ }^{(24-28)}$. There is no study on the effect of prebiotics on soya-based beverages compared with $\mathrm{CM}$ during periods when significant growth occurs. This study was developed as an experimental model with rats, which allows the evaluation of not only food intake but also somatic growth and apparent absorption and retention, and also analyses the performance that may address our objective. In consideration of the abovementioned view, the objective of the study was to evaluate the effects of FOS supplementation in SB on intestinal absorption of $\mathrm{Ca}$ and $\mathrm{Fe}$, dietary intake, body growth, intestinal weight and caecal $\mathrm{pH}$ in recently weaned rats compared with recently weaned rats fed with $\mathrm{CM}$ with and without FOS.

\section{Methods}

\section{Animals and diets}

A total of thirty-two male Wistar rats, 21-d-old (on the first day of weaning), were taken from the Experimental Models Development Centre (Centro de Desenvolvimento de Modelos Experimentais - CEDEME) of the Federal University of Sao
Paulo (Universidade Federal de São Paulo - UNIFESP) and kept in the Research Laboratory of the Department of Paediatrics of the Federal University of Sao Paulo - Paulista Medical School (Escola Paulista de Medicina), São Paulo, SP, in individual metabolic cages made of acrylic and stainless steel (Nalgene Metabolic Cages 650-0100, Tecniplast) under a light cycle of $12 \mathrm{~h}$ and at a temperature of $23 \pm 1{ }^{\circ} \mathrm{C}$. Each cage was adapted with two troughs previously rinsed in deionised water. The use of these cages prevented coprophagy and the contamination of $\mathrm{Fe}$ and allowed evaluations of apparent absorption and retention because urine and faeces were collected and maintained separately. There were four groups of eight animals each, which received the following diets: cows' milk (CM) - animals that received lactose-free $\mathrm{CM}$; cows' milk + FOS (CMF) - animals that received lactose-free CM supplemented with FOS $(0 \cdot 8 \mathrm{~g} / 100 \mathrm{ml})$; soya beverage (SB) - animals that received soya extract-based beverage; and soya beverage + FOS (SBF) - animals that received soya extract-based beverage supplemented with FOS $(0.8 \mathrm{~g} /$ $100 \mathrm{ml}$ ). The CM and CMF groups were considered as control groups.

\section{Dietary intake and diet composition}

During the entire study period (seven consecutive days), the animals received deionised water from a MilliQ Plus system (Millipore Indústria e Comércio Ltda.) and a liquid diet ad libitum. The volumes consumed were measured daily, and the troughs were sanitised at each meal change (diet split two times a day: $50 \mathrm{ml}$ in the morning and $100 \mathrm{ml}$ in the evening). Water $(100 \mathrm{ml})$ was offered once a day.

Food intake was determined according to the ingested volume within $7 \mathrm{~d}$ of the experiment. Evaluation of the daily food intake allowed the calculation of the feed efficiency coefficient, which was expressed as follows: weight gain (g)/intake of ingested diet ( $\mathrm{ml})$.

Regarding SB, a well-known and widely marketed brand in the Brazilian market with an original flavour was used. Ultrahigh temperature CM, semi-skimmed without lactose was also used. Regarding the nutritional content, the values declared on the labels were considered, except for the Fe and Ca contents,

Table 1. Nutritional composition of the diets offered during the experiment according to the information on the label of each product

\begin{tabular}{|c|c|c|c|c|}
\hline Contents (per $100 \mathrm{ml}$ ) & $\mathrm{CM}+$ & CMF† & SBł & SBF \\
\hline Energy (kJ) & 172 & 172 & 172 & 172 \\
\hline Carbohydrate (g) & 4.5 & 4.5 & $4 \cdot 2$ & $4 \cdot 2$ \\
\hline Lipid (g) & $1 \cdot 2$ & $1 \cdot 2$ & 1.6 & 1.6 \\
\hline Protein (g) & $3 \cdot 1$ & $3 \cdot 1$ & 2.6 & 2.6 \\
\hline $\mathrm{Ca}(\mathrm{mg})^{*}$ & 128 & 128 & 128 & 128 \\
\hline $\mathrm{Fe}(\mathrm{mg})^{*}$ & 0.3 & 0.3 & 0.6 & 0.6 \\
\hline $\mathrm{Na}(\mathrm{mg})$ & 64 & 64 & 81 & 81 \\
\hline Vitamin C $(\mu \mathrm{g})$ & - & - & 3.4 & 3.4 \\
\hline Vitamin D $(\mu \mathrm{g})$ & - & - & 1 & 1 \\
\hline Fibre (g) & 0 & 0 & 1.0 & $1 \cdot 0$ \\
\hline Fructo-oligosaccharides (g) & - & 0.8 & - & 0.8 \\
\hline
\end{tabular}

$\mathrm{CM}$, animals fed lactose-free cows' milk; CMF, animals fed lactose-free cows' milk supplemented with fructo-oligosaccharides; SB, animals fed with soyabased beverage; SBF, animals fed with soya-based beverage supplemented with fructo-oligosaccharides.

* Value determined by laboratory analysis.

$\dagger$ Ingredients of CM and CMF according to manufacturer's information: semi-skimmed milk, lactase enzyme and stabilisers sodium citrate, sodium triphosphate, sodium monophosphate and sodium diphosphate.

‡ Ingredients of SB and SBF according to manufacturer's information: soya extract, water, sugar, vitamins $\left(C, E, B_{2}, B_{6}, A\right.$, folic acid, D and $\left.B_{12}\right)$, minerals $(\mathrm{Ca}, \mathrm{Zn})$, salt, stabilisers gellan gum, trisodium citrate and xanthan gum, flavouring and emulsifying soya lecithin. 
which were obtained by chemical analysis, tested in triplicate, from different batches and performed in the Laboratory of Food Science and Microbiology of the Federal University of São Paulo - Paulista Medical School, São Paulo, SP, Brazil using standardised techniques. The full nutrient composition of the diets and ingredients used were reported in Table 1.

In the present study, the cows' milk control groups (CM and $\mathrm{CMF}$ ) received lactose-free $\mathrm{CM}$, considering that in previous studies, it was verified that the weaned animals that received infant formulas with lactose presented with higher amounts of softened faeces, which may suggest lactose malabsorption ${ }^{(29,30)}$. Thus, lactose-free CM, such as soya extract-based beverage, was used.

The prebiotic dose (FOS) used in the study was given at the concentration of $0.8 \mathrm{~g}$ for each $100 \mathrm{ml}$, analogous to commercialised infant formulas; in addition, this dose is the maximum value recommended by the National Sanitary Surveillance Agency (Agência Nacional de Vigilância Sanitária - ANVISA) ${ }^{(31)}$. Furthermore, as observed in previous pilot studies in our laboratory, supplementation with this prebiotic concentration did not promote diarrhoea in the animals.

\section{Experimental procedures}

The experiment was performed in two stages. Each stage had 16 animals, with a total of thirty-two rats. They were divided into four groups of four rats in each group. On the first day of the study, four similar groups were formed, and the animals were weighed and measured. The weights were measured with a digital electronic scale, CG-Libror L-600 (CG Instrumentos Científicos Ltda.), with a maximum capacity of $600 \mathrm{~g}$ and a sensitivity of $0 \cdot 1 \mathrm{~g}$. The length was expressed in centimetres, considering the body and tail measurements. These same procedures were repeated on the fourth and seventh day ( $28 \mathrm{~d}$ of animal life).

On the second day of the experiment, faecal occult blood tests were performed on each animal using the Hemoplus kit (Newprov - Produtos para Laboratórios Ltda.). This same procedure was repeated on the seventh day.

From the third day of the experiment, stool collection was performed to determine faecal balance and subsequent calculation of apparent $\mathrm{Ca}$ and Fe absorption levels. For this assay, $0 \cdot 1 \mathrm{~g}$ of pink-carmine dye $\left(\right.$ Merck $\left.^{\circledR}\right)$ was added to the diet of each animal, and for three consecutive days, the eliminated faeces were collected from the time the colour change (reddish) occurred. After $72 \mathrm{~h}$ of the addition of rose-carmine, Evans blue dye (Inlab, soluble in water) was added to the diets. The collection was interrupted at the beginning of bluish colour faeces elimination. The faeces collected during the $3 \mathrm{~d}$ were weighed on an analytical electronic scale (Metler Toledo - model AB204), with a sensitivity of $0 \cdot 0001 \mathrm{~g}$, and stored in a freezer ($20^{\circ} \mathrm{C}$ ). During the same period of faeces collection, all of the eliminated urine were also collected for further determination of apparent Ca retention. The urine collected during these three consecutive days was duly identified, measured with a glass test tube and stored at $-20^{\circ} \mathrm{C}$.

At $28 \mathrm{~d}$ of age (the seventh day of the experiment), the animals were previously anaesthetised with ketamine and xylazine
(66.6 and $13.3 \mathrm{mg} / \mathrm{kg}$, respectively), and blood from the heart was collected and centrifuged at $2500 \mathrm{rpm}$ for $15 \mathrm{~min}$ to obtain serum, which was stored at $-80^{\circ} \mathrm{C}$ for further analysis of serum $\mathrm{Ca}$ and 25-hydroxyvitamin D (25(OH)D). In addition, small blood samples $(0 \cdot 1 \mathrm{ml})$ from the heart were collected and separated for determination of $\mathrm{Hb}$ and haematocrit $(\mathrm{Ht})$. Afterwards, the animals were submitted to euthanasia by exsanguination of the vena cava.

A median incision of the abdominal wall and peritoneum was performed, and the duodenum (standardising $5 \mathrm{~cm}$ of the pylorus) and caecum (sectioning it between the ileocaecal valve and the beginning of the proximal colon) were isolated. After the caecum, the colon was separated. Next, liver excision was performed. All intestinal portions and organs were weighed fresh, after washing with physiological saline to withdraw the contents of the lumen, weighed on an analytical electronic scale (Shimadzu model AY220) with a sensitivity of $0.0001 \mathrm{~g}$ and placed immediately in liquid nitrogen, stored at $-80^{\circ} \mathrm{C}$ and used for quantification of divalent metal transporter 1 (DMT1), ferroportin and hepatic Fe. At that time, the $\mathrm{pH}$ of the caecal contents was also evaluated. For this assay, the animals were sacrificed between 06.00 and 10.00 hours, during which time the intestinal fermentation is more active (Younes et al., 2001). The $\mathrm{pH}$ of the caecal content was measured with disposable $\mathrm{pH}$ test strips, $\mathrm{PHBIO}{ }^{\circledR}$ (Photogenesis Biotecnologia).

\section{Dose of serum calcium and 25-hydroxyvitamin D}

The serum Ca level was determined using a colorimetric method, and the $25(\mathrm{OH}) \mathrm{D}$ dosage was determined using a chemiluminescence method.

\section{Apparent absorption of calcium and iron}

To determine the apparent absorption of $\mathrm{Ca}$ and $\mathrm{Fe}$, the faeces collected for $72 \mathrm{~h}$ were then dried in an oven at $105^{\circ} \mathrm{C}$, and after $22 \mathrm{~h}$, they were weighed at intervals of $30 \mathrm{~min}$, until two consecutive weights were obtained with less than $1.0 \mathrm{mg}$ of difference. Stool moisture was calculated using the formula (((faeces fresh weight-faeces dry weight)/faeces fresh weight $) \times 100)^{(32)}$.

Subsequently, $500 \mathrm{mg}$ of dry faeces from each animal was separated into two $250 \mathrm{mg}$ (duplicate) samples, which were subjected to liquid digestion using nitric acid and perchloric acid (volumes: $4 \mathrm{ml}$ of nitric acid and $2 \mathrm{ml}$ of perchloric acid; temperature of the digester: $200^{\circ} \mathrm{C}$; wavelengths: Fe: $248.3 \mathrm{~nm}$, Ca: $422.7 \mathrm{~nm}$, slit: $0.7 \mathrm{~nm}$, flame air/acetylene, energy: Fe: 60, Ca: 67) and then diluted in lanthanum chloride $\left(\right.$ Merck $^{\circledR}$ ) to a final concentration of $1 \%$ for Ca analysis and in deionised water for Fe analysis, allowing the evaluation in an atomic absorption spectrophotometer ${ }^{\text {(33) }}$ (Perkin-Elmer model $5100 \mathrm{PC}$ ). The amounts of $\mathrm{Ca}$ and $\mathrm{Fe}$ ingested over the same period of time were also calculated. The percentage of $\mathrm{Ca}$ absorbed was calculated using the following formula ${ }^{(34)}$ : ( ((amount of ingested $\mathrm{Ca}$-amount of excreted faecal Ca)/amount of ingested $\mathrm{Ca}) \times 100$ ). Absorption of $\mathrm{Fe}$ was calculated with a similar formula ${ }^{(31)}$. 


\section{Apparent retention of calcium}

To determine the apparent retention of $\mathrm{Ca}$, the urine collected during the faeces collection period was subsequently filtered on filter paper (Whatman Filter Papers 40, ashless, circles, $90 \mathrm{~mm} \varnothing$, Whatman Corp.) and diluted, allowing evaluation using an atomic absorption spectrophotometer ${ }^{(35)}$. For analysis of $\mathrm{Ca}$, lanthanum chloride $\left(\right.$ Merck $^{\circledR}$ ) was added to the samples (final concentration: $0.5 \%$ lanthanum). Thus, the following formula was used to calculate the percentage of retained Ca: (((amount of ingested $\mathrm{Ca}$-amount of faecal $\mathrm{Ca}$ excreted-amount of excreted urinary $\mathrm{Ca}$ )/amount of ingested $\mathrm{Ca}$ ) $\times 100$ ).

\section{$\mathrm{Hb}$ and haematocrit concentrations}

The $\mathrm{Hb}$ concentration was determined using the cyanmethaemoglobin method, and the microhaematocrit was determined using the Wintrobe method ${ }^{(36)}$.

\section{Hepatic iron}

The determination of hepatic Fe was also performed after liquid digestion of dry tissue, similar to that cited for faeces ${ }^{(32)}$. For this, the livers collected on the sacrifice day were oven dried at $120^{\circ} \mathrm{C}$ and after $22 \mathrm{~h}$, they were weighed at intervals of $30 \mathrm{~min}$, until two consecutive weighings with a difference of less than $1.0 \mathrm{mg}$ were obtained. Subsequently, $500 \mathrm{mg}$ of dried livers of each animal were weighed, divided into two $250 \mathrm{mg}$ (duplicate) samples that were submitted to liquid digestion using nitric acid and perchloric acid, making possible the evaluation in atomic absorption spectrophotometer.

\section{Western blot analysis}

Samples of the duodenum, caecum and colon were placed in $800 \mu \mathrm{l}$ of specific buffer, prepared on the day of the experiment, with the following composition to obtain total protein extracts: 100 mм Trizma base $\mathrm{pH} 7 \cdot 5,20 \mathrm{~mm}$ ethylenediaminetetraacetic acid, $100 \mathrm{~mm}$ sodium fluoride, sodium pyrophosphate $100 \mathrm{~mm}$, $10 \mathrm{~mm}$ sodium orthovanadate, $2 \mathrm{~mm}$ phenylmethylsulfonyl fluoride and $0 \cdot 1 \mathrm{mg} / \mathrm{ml}$ aprotinin. The tissues were quickly homogenised using a Polytron homogeniser, and $800 \mu \mathrm{l}$ of $1 \%$ Triton $\mathrm{X}-100$ was then added and incubated for $30 \mathrm{~min}$. The homogenate was centrifuged for $40 \mathrm{~min}$ at $14000 \mathrm{rpm}$ at $4^{\circ} \mathrm{C}$. The supernatant was kept on ice, and the total protein content was determined by the Bradford method (Bio-Rad), which uses bovine serum albumin as a reference.

Protein samples were added to Laemmli buffer (0.01\% bromophenol blue, $100 \mathrm{~mm}$ sodium phosphate $\mathrm{pH} 7 \cdot 0,50 \%$ glycerol and $10 \%$ sodium dodecyl sulphate) at the ratio of $4: 1$ with $100 \mathrm{~mm}$ dithiothreitol. Volumes containing $75 \mu \mathrm{g}$ of protein (caecum and colon) and $100 \mu \mathrm{g}$ of protein (duodenum) were heated for $5 \mathrm{~min}$ before being subjected to $10 \%$ denaturing sodium dodecyl sulphate-polyacrylamide gel electrophoresis in a Bio-Rad miniature slab gel apparatus. After electrophoresis, the samples were electrophoresed to nitrocellulose membrane for $1.5 \mathrm{~h}$ per four gels at room temperature at $15 \mathrm{~V}$ (constant) in a semi-dry transfer apparatus (Bio-Rad). To reduce non-specific protein binding, the membrane was blocked in $5 \mathrm{ml}$ of a blocking solution $(100 \mathrm{~mm}$ Trizma base $\mathrm{pH} 7 \cdot 5,500 \mathrm{~mm} \mathrm{NaCl}, 500 \mu \mathrm{l} / \mathrm{ml}$ Tween-20) containing $1 \%$ bovine serum albumin for $4 \mathrm{~h}$. Subsequently, the membrane was incubated overnight at $22^{\circ} \mathrm{C}$ in blocking solution with primary antibodies against DMT1 (1:1000 - Santa Cruz Biotechnology) and ferroportin (1:1000 - Santa Cruz Biotechnology) or $\beta$-tubulin (1:10 000 - Cell Signaling Technology). The membranes were washed for $30 \mathrm{~min}$ in basal solution, shaken every $10 \mathrm{~min}$ and then incubated with the respective peroxidase-conjugated secondary antibodies for $1 \mathrm{~h}$ at $22^{\circ} \mathrm{C}$. The secondary antibodies were anti-goat for ferroportin (1:5000), anti-mouse for DMT1 (1:5000) and anti-rabbit for $\beta$-tubulin (1:5000) (Sigma). The membranes were then resubjected to $30 \mathrm{~min}$ of lavage with basal solution with shaking every $10 \mathrm{~min}$ and were then incubated with enhanced chemiluminescence Reagent from Amersham/GE and exposed to an Alliance 4.7 device (Uvitec) for photo documentation. The intensities of the bands of interest were identified by the electrophoretic migration patterns and quantified by optical densitometry using the Scion Image program (Scion Image-Released Beta 3b).

\section{Statistical analysis}

The data were submitted to the Shapiro-Wilk (normality), Levene (homogeneity) and/or Mauchly (sphericity) quality tests. When necessary, the data were standardised for Naperian Log. Two-way ANOVA or ANOVA for repeated measures was used to verify the effects of treatment and comparisons between groups, followed by post hoc Tukey or Kruskal-Wallis tests, followed by Dunn when necessary. All statistical tests were performed in SigmaPlot 12.0, and the other tasks were performed in Microsoft Excel 2016 and GraphPad Prism 5.0. The results are expressed as the means \pm standard errors of the mean (SEM) or medians and 25th and 75th percentiles when necessary, and the level of significance was set at $P<0.05$.

Sample size calculation was based on a preliminary experiment. It was calculated that at least three samples in each group were needed to reach significance level between study groups when differences of $P$ values $<0.05$ was assumed.

\section{Ethical considerations}

All animal care and use procedures were approved (CEUA 3498100315) by the Experimental Research Ethics Committee of the Federal University of São Paulo and performed in accordance with the relevant institutional and national guidelines, and the manuscript conform to the ARRIVE Guidelines for Reporting Animal Research.

\section{Results}

\section{Baseline data}

Three animals were excluded from the sample because they did not complete the entire study period due to post-anaesthesia death without apparent cause. One animal was from the CM group, one was from the $\mathrm{CMF}$ group and the other was from the SB group. 
Table 2. Calcium intake, iron intake and feed efficiency during the $7 \mathrm{~d}$ of the experiment in rat pups from the four diet groups ${ }^{\star}$ (Mean values with their standard errors)

\begin{tabular}{|c|c|c|c|c|c|c|c|c|}
\hline \multirow[b]{2}{*}{ Variables } & \multicolumn{2}{|c|}{$\mathrm{CM}(n 7)$} & \multicolumn{2}{|c|}{ CMF $(n 7)$} & \multicolumn{2}{|c|}{$\mathrm{SB}(n 7)$} & \multicolumn{2}{|c|}{$\operatorname{SBF}(n 8)$} \\
\hline & Mean & $\mathrm{SE}$ & Mean & SE & Mean & SE & Mean & SE \\
\hline Volume of diet intake (ml) & $442 \cdot 86$ & $12 \cdot 22$ & 409.29 & $20 \cdot 26$ & $429.57 \dagger$ & $15 \cdot 65$ & 373.38 & 14.63 \\
\hline Ca intake $(\mathrm{mg})$ & 566.86 & $15 \cdot 65$ & 523.89 & 25.93 & $549.85 \dagger$ & $20 \cdot 03$ & 477.92 & 18.72 \\
\hline Fe intake (mg) & 1.51 & 0.04 & 1.39 & 0.07 & $2.92 \ddagger \S$ & 0.11 & $2.54 \|$ & 0.10 \\
\hline Weight gain (g) & $24 \cdot 16 \pi$ & $2 \cdot 39$ & 24.33 & 2.55 & $15 \cdot 85$ & 0.65 & $14 \cdot 10 \|$ & 1.34 \\
\hline $\mathrm{FEC}(\mathrm{g} / \mathrm{ml})$ & $0.05^{\star \star}$ & 0.00 & 0.06 & 0.00 & 0.04 & 0.00 & $0.04 \|$ & 0.00 \\
\hline
\end{tabular}

$\mathrm{CM}$, animals fed lactose-free cows' milk; CMF, animals fed lactose-free cows' milk supplemented with fructo-oligosaccharides; SB, animals fed with soya-based beverage; SBF, animals fed with soya-based beverage supplemented with fructo-oligosaccharides; FEC, feed efficiency coefficient.

* Two-way ANOVA test.

$\dagger P=0.018 v$. SBF

$\ddagger P=0.004$ v. SBF

$\S P<0.001$ v. CM.

$\| P<0.001$ v. CMF.

I $P=0.005$ v. SB.

** $P=0.004$ v. SB

\section{Food consumption, feed efficiency coefficient and} weight gain

Table 2 shows the mean food intake (volume of ingested diet, $\mathrm{Ca}$ intake and Fe consumption), the feed efficiency coefficient and weight gain.

The mean volume of consumed diet in the $\mathrm{CM}, \mathrm{CMF}, \mathrm{SB}$ and SBF groups were 442.86 (SE 12.22), 409.29 (SE 20.26), $429 \cdot 57$ (SE 15.65) and 373.38 (SE 14.63$) \mathrm{ml}$, respectively $(P<0.05)$. The volume of consumed diet was significantly higher in the SB group compared with the SBF group $(P=0 \cdot 018)$.

The mean $\mathrm{Ca}$ intake in the $\mathrm{CM}, \mathrm{CMF}, \mathrm{SB}$ and $\mathrm{SBF}$ groups were 566.86 (sE 15.65), 523.89 (se 25.93), 549.85 (sE 20.03) and 477.92 (se 18.72$) \mathrm{mg}$, respectively $(P<0.05)$, and those of the Fe intake were 1.51 (SE 0.04), 1.39 (SE 0.07), 2.92 (SE 0.11) and 2.54 (sE $0 \cdot 10) \mathrm{mg}$, respectively $(P<0 \cdot 05)$. Ca intake in the SB group was higher in relation to the SBF group $(P=0 \cdot 018)$. The SB group had significantly higher Fe consumption than the $\mathrm{CM}$ $(P<0.001)$ and SBF $(P=0.004)$ groups. In addition, the SBF group presented significantly higher Fe consumption compared with the CMF group $(P<0 \cdot 001)$.

The mean weight gain in the $\mathrm{CM}, \mathrm{CMF}, \mathrm{SB}$ and $\mathrm{SBF}$ groups were 24.16 (sE 2.39), 24.33 (sE 2.55), 15.85 (sE 0.65) and 14.10 (SE 1.34) g, respectively $(P<0.05)$, and those of the feed efficiency coefficient were 0.05 (SE 0.00), 0.06 (SE 0.00), 0.04 (se 0.00$)$ and $0.04 \quad(\mathrm{se} \quad 0.00) \mathrm{g} / \mathrm{ml}$, respectively $(P<0.05)$. Throughout the experiment, weight gain was significantly higher in the CM group compared with the SB group $(P=0.005)$ and in the SBF group compared with the CMF group $(P<0 \cdot 001)$. The feed efficiency coefficient $(\mathrm{g} / \mathrm{ml})$ of the $\mathrm{CM}$ group was higher when compared with the SB group $(P=0.004)$. The feed efficiency coefficient $(\mathrm{g} / \mathrm{ml})$ was also significantly higher in the SBF group compared with the CMF group $(P<0 \cdot 001)$.

Weights of different portions of the intestine and liver and $\mathrm{pH}$ of the caecal content

There were no significant differences between the groups regarding the rats' duodenum, colon or liver weights in the $\mathrm{CM}$, $\mathrm{CMF}, \mathrm{SB}$ and $\mathrm{SBF}$ groups. The mean duodenum weights were
0.28 (SE 0.03), 0.26 (sE 0.03), 0.23 (sE 0.03) and 0.25 (SE 0.03) g, respectively $(P>0.05)$, and those of the liver were 3.09 (SE 0.20), 3.17 (sE 0.23), 2.87 (sE 0.16) and 2.63 (sE 0.20) g, respectively $(P>0.05)$. The medians and 25 th and 75 th percentiles of the colon were $0.41(0.32-0.48), 0.45(0.34-0.63), 0.46(0.44-0.68)$ and $0.46(0.43-0.59) \mathrm{g}$, respectively $(P>0.05)$. The mean caecum weights in the CM, CMF, SB and SBF groups were 1.89 (SE 0.33), 3.81 (sE 0.38), 1.53 (sE 0.13) and 3.50 (sE 0.35) g, respectively $(P<0 \cdot 001)$, with significant differences between the CMF and CM groups $(P<0.001)$ and between the SBF and SB groups $(P<0 \cdot 001)$. There was no significant difference between the groups that received prebiotics $(P>0.05)$. The medians and 25 th and 75 th percentile values of the caecal content $\mathrm{pH}$ levels in the CM, CMF, SB and SBF groups were 8.00 (8.00-8.00), 6.00 (6.00-7.00), 7.00 (7.00-7.00) and 6.00 (5.00-6.00), respectively, with a significant difference between the CMF and CM groups $(P<0.05)$ and between the SBF and SB groups $(P<0.05)$. No significant difference was observed among the groups that received prebiotics $(P>0 \cdot 05)$.

\section{Serum calcium concentration, 25-hydroxyvitamin D, apparent absorption and retention of calcium}

The mean serum $\mathrm{Ca}$ in the $\mathrm{CM}, \mathrm{CMF}, \mathrm{SB}$ and $\mathrm{SBF}$ groups were 11.00 (sE 0.34), 11.57 (sE 0.36), 12.06 (sE 0.63) and 11.64 (sE $0 \cdot 29) \mathrm{mg} / \mathrm{dl}$, respectively $(P>0 \cdot 05)$. No significant differences were found between the groups when the serum Ca concentration was analysed (Fig. 1(a)).

The mean serum concentration of $25(\mathrm{OH}) \mathrm{D}$ in the $\mathrm{CM}, \mathrm{CMF}$, SB and SBF groups were 15.12 (SE 1.76), $25 \cdot 56$ (SE 5.10), 35.64 (sE 2.42 ) and $39 \cdot 18$ (sE 5.68) ng/ml, respectively ( $P>0.05$ ). In the SB group, the serum concentration of $25(\mathrm{OH}) \mathrm{D}$ was higher compared with the CM group $(P=0 \cdot 003)$. In addition, the serum concentration of $25(\mathrm{OH}) \mathrm{D}$ in the SBF group was higher compared with the CMF group $(P=0 \cdot 032)$ (Fig. 1(b)).

The mean apparent $\mathrm{Ca}$ absorption in the $\mathrm{CM}, \mathrm{CMF}, \mathrm{SB}$ and SBF groups were 73.44 (SE 2.72), 78.04 (SE 2.84), 50.71 (SE 1.94) and 58.29 (se 3.81$) \%$, respectively $(P>0.05)$, and those of the apparent retention of $\mathrm{Ca}$, the medians and 25 th and 75 th percentiles were 75.41 (66.10-79.24), 76.29 (68.25-81.49), 
(a)

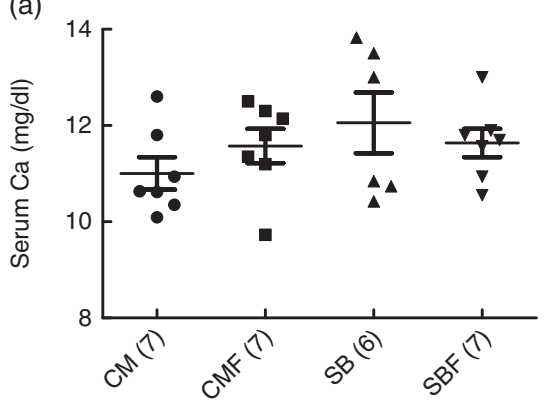

(c)

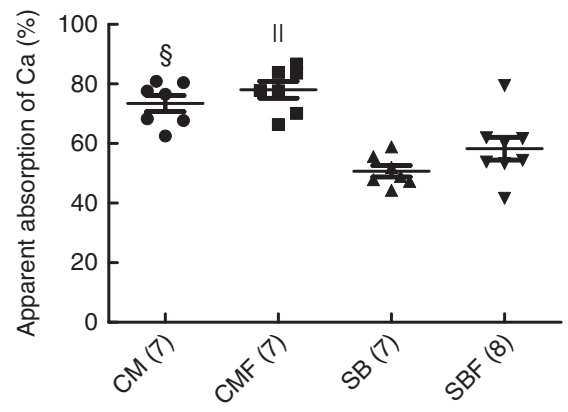

(b)

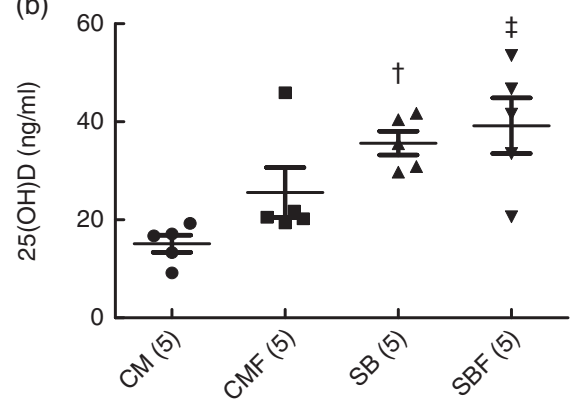

(d)

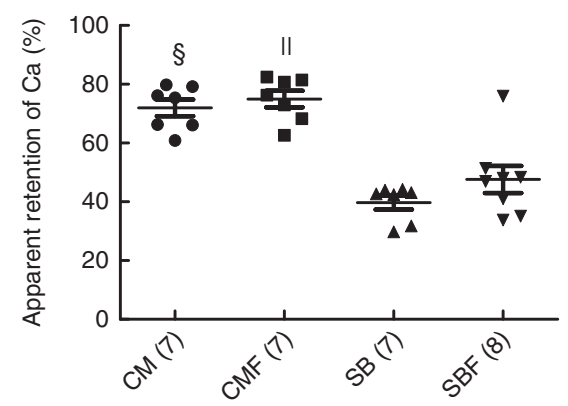

Fig. 1. Serum calcium concentration (a), serum concentration of 25-hydroxyvitamin $D(25(\mathrm{OH}) \mathrm{D})(\mathrm{b})$, apparent absorption of calcium (c) and apparent retention of calcium (d). CM, animals fed lactose-free cows' milk; CMF, animals fed lactose-free cows' milk supplemented with fructo-oligosaccharides; SB, animals fed with soyabased beverage; SBF, animals fed with soya-based beverage supplemented with fructo-oligosaccharides. Values are means with their standard errors. Two-way ANOVA test or Kruskal-Wallis test. The number in parentheses refers to the sample size. $\dagger P=0.003 v$. CM. $\ddagger P=0.032 v$. CMF. $§ P<0.001 v$. SB. $\| P<0.001 v$. SBF. To convert calcium in $\mathrm{mg} / \mathrm{dl}$ to $\mathrm{mmol} / \mathrm{l}$, multiply by 0.25 .

42.74 (31.79-43.98) and 47.51 (36.64-50.64)\%, respectively $(P>0 \cdot 05)$. The apparent $\mathrm{Ca}$ absorption, evaluated for $72 \mathrm{~h}$, which considered the difference between the total ingested and the total excreted in the faeces, was significantly greater in the $\mathrm{CM}$ group than in the SB group $(P<0 \cdot 001)$. In addition, the apparent absorption of $\mathrm{Ca}$ in the $\mathrm{CMF}$ group was higher in relation to that in the SBF group $(P<0.001)$ (Fig. 1(c)). Regarding the apparent retention of $\mathrm{Ca}$ evaluated over $72 \mathrm{~h}$, which considered the differences between the total ingested and total excreted in the faeces and urine, retention was significantly higher in the CM group than in the SB group $(P<0 \cdot 001)$. In addition, a significantly greater apparent retention of $\mathrm{Ca}$ was observed in the CMF group compared with the SBF group $(P<0 \cdot 001)$ (Fig. 1(d)).

\section{$\mathrm{Hb}$ concentration, haematocrit, apparent iron absorption and hepatic iron content}

The mean $\mathrm{Hb}$ concentrations in the $\mathrm{CM}, \mathrm{CMF}, \mathrm{SB}$ and $\mathrm{SBF}$ groups were 5.42 (sE 0.17), 7.84 (sE 0.58), 9.77 (sE 0.67) and 11.83 (SE 0.64$) \mathrm{g} / \mathrm{dl}$, respectively $(P<0.05$ ), and those of the $\mathrm{Ht}$ concentrations were 19.25 (SE 1.11), 25.43 (SE 1.48), 32.57 (SE $1.19)$ and 37.83 (se 1.54$) \%$, respectively $(P<0.05)$. At the end of the experiment, the $\mathrm{Hb}$ concentrations of the $\mathrm{CMF}$ and $\mathrm{SB}$ groups were significantly higher compared with the CM group ( $P=0.025$ and $P<0.001$, respectively). In addition, in the SBF group, the $\mathrm{Hb}$ concentration was higher compared with the $\mathrm{SB}$ and CMF groups $(P=0.030$ and $P<0.001$, respectively) (Fig. 2(a)). Likewise, the Ht concentrations in the CMF and SB groups were higher in relation to the $\mathrm{CM}$ group $(P=0 \cdot 010$ and $P<0 \cdot 001$, respectively). In addition, the $\mathrm{Ht}$ concentration was higher in the SBF group than in the SB and CMF groups $(P=0.013$ and $P<0 \cdot 001$, respectively) (Fig. 2(b)).

The medians and 25th and 75th percentiles apparent $\mathrm{Fe}$ absorption in the CM, CMF, SB and SBF groups were 94.27 (92.80-94.86), 94.92 (94.18-96.62), 37.61 (26.63-79.24) and $42.27(28 \cdot 62-53.57) \%$, respectively $(P<0.05)$. The apparent $\mathrm{Fe}$ absorption in the $\mathrm{CM}$ group was significantly higher when compared with the SB group $(P<0 \cdot 001)$. Furthermore, in the CMF group, the apparent Fe absorption was higher in relation to the SBF group $(P<0 \cdot 001)$ (Fig. 2(c)).

The mean hepatic Fe content in the CM, CMF, SB and SBF groups were 70.39 (SE 5.86), 70.85 (SE 5.43), 68.23 (SE 15.81) and 98.83 (sE 13.39$) \mu \mathrm{g} / \mathrm{g}$, respectively $(P>0.05)$. Regarding hepatic Fe content, no significant differences were found between the groups (Fig. 2(d)).

Protein expression of the divalent metal transporter 1 and ferroportin in the intestines

Regarding ferroportin protein expression in the duodenum, caecum and colon, no differences were found between the groups (Fig. 3(a) and (b)). The mean ferroportin protein expression in the duodenum were 100.00 (sE 10.84), 79.51 (SE 18.25), 92.67 (SE 28.39) and 52.66 (SE 8.28) arbitrary units, respectively $(P>0.05)$, and those of the ferroportin protein expression in the caecum were 100.00 (SE 18.63), 158.70 (SE 
(a)

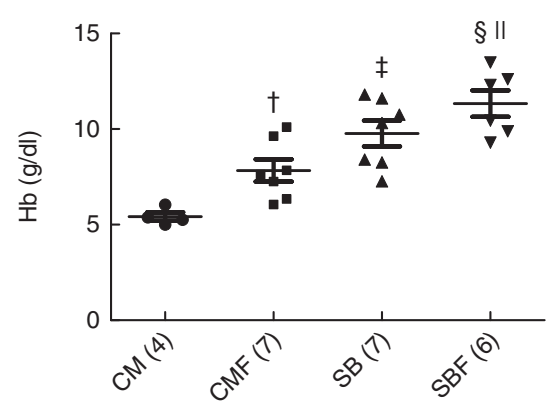

(c)

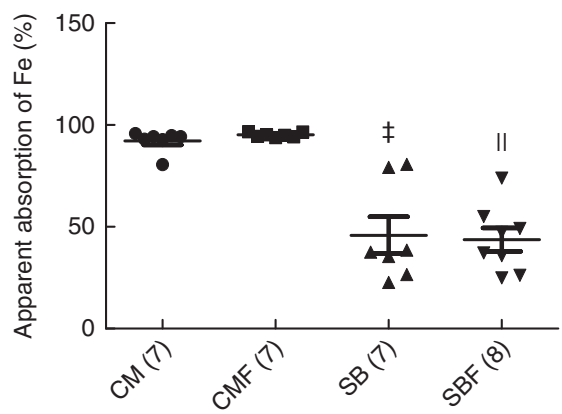

(b)

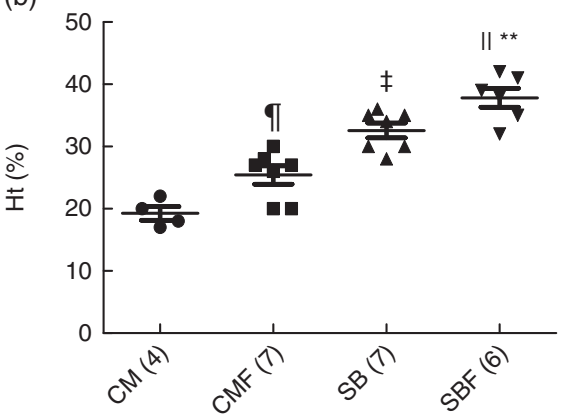

(d)

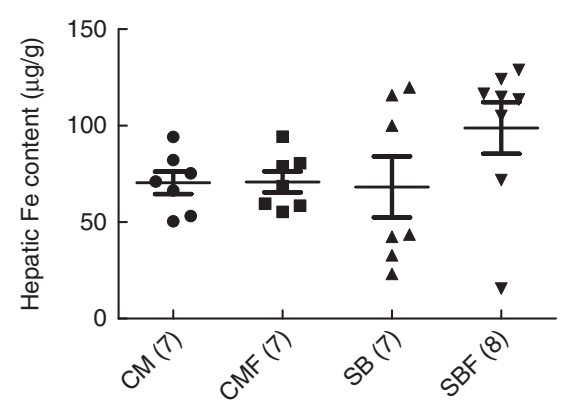

Fig. 2. Hb concentration (a), haematocrit (Ht) concentration (b), apparent absorption of iron (c) and hepatic iron content (d). CM, animals fed lactose-free cows' milk; CMF, animals fed lactose-free cows' milk supplemented with fructo-oligosaccharides; SB, animals fed with soya-based beverage; SBF, animals fed with soya-based beverage supplemented with fructo-oligosaccharides. Values are means with their standard errors. Two-way ANOVA test or Kruskal-Wallis test. The number in parentheses refers to the sample size. $\dagger P=0.025$ v. CM. $\ddagger P<0.001$ v. CM. $\S P=0.030$ v. SB. $\| P<0.001$ v. CMF. $\uparrow P=0.010$ v. CM. ${ }^{\star *} P=0.013$ v. SB. To convert Hb in $\mathrm{mg} / \mathrm{dl}$ to $\mathrm{mg} / \mathrm{l}$, multiply by 10 .

27.73), 117.38 (sE 16.79) and 93.33 (sE 20.42) g, respectively $(P>0.05)$. The mean ferroportin protein expression in the colon were 100.00 (SE 11.68), 89.16 (SE 17.55), 87.87 (SE 22.64) and 118.61 (sE 24.95) arbitrary units, respectively $(P<0.05)$.

The mean DMT1 protein expression in the duodenum were 100.00 (sE 0.00), 72.07 (sE 34.28), 107.82 (sE 38.69) and 280.92 (SE 39.58) arbitrary units, respectively $(P<0 \cdot 05)$. DMT1 protein expression in the duodenum in the SBF group was higher in relation to the $\mathrm{SB}$ and $\mathrm{CMF}$ groups $(P=0.005$ and $P=0.001$, respectively). No differences were found between the groups when DMT1 protein expression was analysed in the caecum and colon (Fig. 3(b)). The mean DMT1 protein expression in the caecum were 100.00 (sE 12.35), 94.60 (sE 23.42), 166.84 (sE 25.40) and 135.36 (se 31.13) arbitrary units, respectively $(P>0.05)$. The mean DMT1 protein expression in the colon were 100.00 (SE 16.86), 109.24 (SE 15.10), 141.39 (SE 24.23) and 113.21 (SE 33.48) arbitrary units, respectively $(P>0.05)$.

\section{Discussion}

The animal model used to conduct the present study was quite satisfactory and showed that the animals fed SB, with and without addition of FOS, presented inferior growth (weight gain) in relation to the animals in the control groups (CM and $\mathrm{CMF})$. It was also observed that in the groups fed SB with and without FOS, there were higher concentrations of $25(\mathrm{OH}) \mathrm{D}$ and lower apparent absorption and retention of Ca. However, there were no increases in serum $\mathrm{Ca}, 25(\mathrm{OH}) \mathrm{D}$ or apparent absorption and retention of $\mathrm{Ca}$ among groups with the addition of FOS. In addition, higher concentrations of $\mathrm{Hb}$ and $\mathrm{Ht}$ and lower apparent Fe absorption were observed in the SB groups, with and without FOS, with the benefit of prebiotic on $\mathrm{Hb}$ and Ht concentrations in the CM and SB groups and DMT1 protein expression in the duodenum in the SB group.

Another point of equal importance is the fact that this is the first study that compares SB in relation to $\mathrm{CM}$ with and without the addition of FOS for a continuous period sufficient to promote significant changes in the nutritional state of the animal. This study used an experimental model previously developed in our laboratory that allowed us to evaluate the nutritional interactions in recently weaned rats exclusively fed on different types of liquid formulas $29,30,37,38)$. During the experiment, the animals did not receive solid feed, with their food intake limited to SB and CM, according to the study group.

Considering the resources available for the research, the total number of animals used was limited. In this sense, it was unnecessary to form a group with conventional feed (e.g. American Institute of Nutrition-93G (AIN-93G)) because the objective of the study was to analyse the interaction of foods (CM, SB and FOS) to simulate what would occur in humans. That is, the feeding strategy was not intended to meet the needs of the animals involved in the experiment ${ }^{(29,30,37,38)}$.

In our study, animals fed FOS in the soya beverage (SBF) consumed less volume of fluid diet than the animals fed with soya beverage without FOS (SB), and consequently, there was less consumption of fluid diet and lower consumption of $\mathrm{Ca}$ and Fe; however, there was no impairment in growth (weight gain) 
(a)
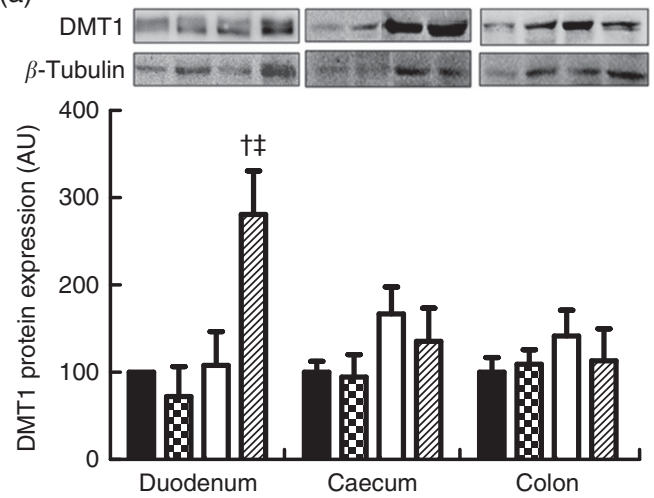

(b)
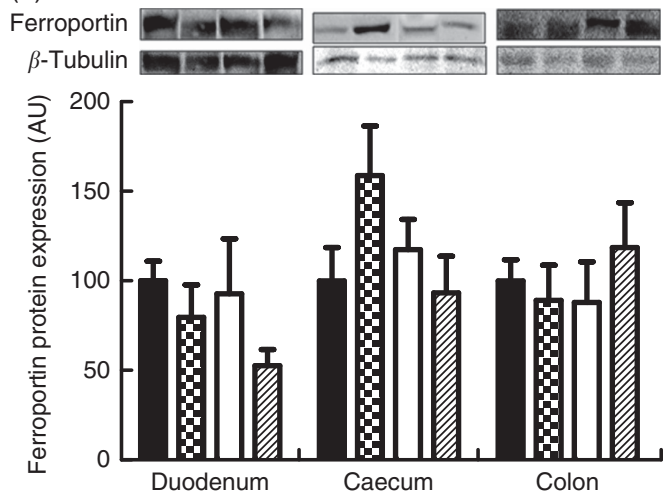

Fig. 3. Protein expression levels of divalent metal transporter 1 (DMT1) (a) and ferroportin (b) in the duodenum, caecum and colon of rat pups from the CM ( $\square$ ), CMF (B), SB $(\square)$ and SBF ( $(Z)$ groups. CM, animals fed lactose-free cows' milk; CMF, animals fed lactose-free cows' milk supplemented with fructooligosaccharides; SB, animals fed with soya-based beverage; SBF, animals fed with soya-based beverage supplemented with fructo-oligosaccharides; $\mathrm{AU}$, arbitrary units. Protein levels were determined by Western blot analysis and normalised to the levels of $\beta$-tubulin. Values are means $(n 3-7)$ with their standard errors represented by vertical bars. $\dagger P=0.005$ v. SB. $\ddagger P=0.001$ v. CMF.

between these groups. This finding is similar to the results of other studies. Freitas et al. ${ }^{(21)}$ and Carvalho et al. ${ }^{(23)}$ did not find significant differences with the use of partially hydrolysed guar gum on growth and body weight of growing rats. Other soluble fibres such as oligofructose and inulin also did not affect the growth of the animals ${ }^{(13,17,22)}$. Thus, it can be speculated that the presence of FOS in the SB provided larger satiety effect in these animals and consequently they had lower consumption dietary.

The results also showed that weight gain was lower in the groups fed with soya beverage (SB and SBF), although dietary intake was similar to that of the control groups (CM and CMF). In a study performed previously in our department ${ }^{(37)}$, weight gain was lower in the groups fed with soya products (soya extract-based beverage and soya-based infant formula) than those fed CM protein-based infant formula. In the present study, this result could also be simply attributed to the nutritional composition of the soya-based beverage having a lower protein content when compared with that of CM. In addition, it is important to remember that soyabean contains antinutritional factors that may interfere with the availability of nutrients, contributing to this finding ${ }^{(39)}$. Another justification may be related to the fact of the lower food efficiency in terms of weight gain per diet consumption in the groups fed with soya beverage.

It is worth noting that despite the differences in weight gain between the four groups, in general, the animals in this experiment presented growth similar to that presented by rats of the same age and fed with conventional feed ${ }^{(40)}$. This aspect is very important because it reinforces the innocuous nature of our experimental model owing to the non-detriment in the growth of animals fed with a liquid diet.

After euthanasia, the fresh weights of the liver, duodenum and colon did not differ among the animals of the four groups, but a significant increase was observed in the weight of the caecum, along with a reduction in the $\mathrm{pH}$ of the caecal contents of the animals of the groups that received CM with FOS and soya beverage with FOS (CMF and SBF) in relation to the animals of the groups without prebiotic ( $\mathrm{CM}$ and $\mathrm{SB}$ ), indicating the effects of FOS in addition to the liquid diets, which would facilitate the solubilisation and absorption of $\mathrm{Ca}$ and $\mathrm{Fe}$. These findings have also been verified in other studies ${ }^{(21-23)}$.

There are only four articles in the literature that have evaluated the absorption of $\mathrm{Ca}$ using SB. However, these studies did not evaluate the effects of prebiotics added to SB when compared with CM.

According to an in vitro study ${ }^{(24)}$ in which the bioavailability of $\mathrm{Ca}$ and zinc from $\mathrm{CM}$ and soya-based foods was evaluated, both with similar Ca contents, it was found that the bioavailability of $\mathrm{Ca}$ is significantly higher in soya-based beverages compared with CM.

Heaney et al. ${ }^{(25)}$ compared the Ca bioavailability of soya beverage (BS) enriched with tricalcium phosphate with that of $\mathrm{CM}$ and demonstrated that the Ca bioavailability of BS corresponded to $75 \%$ of that of $\mathrm{CM}$. The authors suggest that to achieve equivalence of bioavailability between the two beverages, it is necessary that BS be enriched with $500 \mathrm{mg}$ of $\mathrm{Ca} /$ portion and not only with the current $300 \mathrm{mg} /$ portion reported by most manufacturers. This study was performed based on labelled isotope analysis in 16 men aged 22-51 years old.

Zhao et $a l .{ }^{(26)}$ compared Ca absorption from SB enriched with tricalcium phosphate and calcium carbonate in relation to $\mathrm{CM}$ in 20 healthy young women with a mean of 23 years of age and verified that the $\mathrm{Ca}$ absorption with the $\mathrm{SB}$ enriched with $\mathrm{Ca}$ carbonate was similar to that of $\mathrm{CM}$, and both presented better results when compared with $\mathrm{SB}$ enriched with tricalcium phosphate.

Tang et al. ${ }^{(27)}$ compared the absorption of Ca of SB enriched with $\mathrm{Ca}$ phosphate compared with $\mathrm{CM}$ in 12 osteopaenic postmenopausal women and showed that the absorption of $\mathrm{Ca}$ from the enriched soya milk was comparable with that of CM.

Raw soyabean contains antinutritional factors capable of provoking negative effects on human health. Among them, phytates are prominent, which can interact with minerals such as $\mathrm{Ca}$, reducing their absorption ${ }^{(2,7,8)}$. Phytic acid has long been considered an antinutritional factor because it can form complexes with proteins and metal ions, preventing the ideal absorption of minerals from the intestine ${ }^{(9)}$. In this sense, high levels of phytate in the SB decrease the bioavailability of many minerals, including $\mathrm{Ca}$ and $\mathrm{Fe}^{(10)}$. 
Although differences in the apparent absorption and retention of $\mathrm{Ca}$ are observed between the groups, in which the values were greater in the CM group compared with those of the SB group and the CMF group, they were higher in relation to the SBF group; however, serum Ca did not present this same effect. It is known that serum $\mathrm{Ca}$ reflects instantaneous absorption. However, the observed increase tends to be small because $\mathrm{Ca}$ homeostasis prevents extensive modifications. Therefore, this method of detection presents low sensitivity ${ }^{(41)}$. In addition, it should be noted that the time of study was insufficient, thus impacting serum Ca.

Regarding $25(\mathrm{OH}) \mathrm{D}$, it can be assumed that the higher concentrations found in the groups fed with soya beverage (SB and $\mathrm{SBF}$ ) may have been influenced by a defence mechanism to increase the apparent $\mathrm{Ca}$ absorption in these animals because the apparent absorption of $\mathrm{Ca}$ in these groups was smaller. It is important to note that this effect was not verified in another study, which is a hypothesis based on the present study and guided by the mechanisms related to the intestinal absorption of $\mathrm{Ca}$, considering that the main action of calcitriol that contributes to elevate the calcemia is the stimulation of the intestinal absorption of $\mathrm{Ca}$. In addition, it can be speculated that the presence of vitamin $\mathrm{D}$ in SB composition could be another contributing factor for the higher concentration of $25(\mathrm{OH}) \mathrm{D}$ in animals fed SB with and without FOS, whereas there was no vitamin $\mathrm{D}$ in the $\mathrm{CM}$ diet.

In this experiment, the animals fed soya beverage without FOS (SB) presented lower apparent absorption and retention of Ca than the animals fed with cows' milk without FOS (CM). Apparently, our results are in agreement with Zhao et al. and Tang et al., with no difference in serum $\mathrm{Ca}$ concentration between treatments.

Regarding Fe, only one study was found in the literature in which Fe absorption with SB was evaluated in comparison to CM. In this in vitro study ${ }^{(28)}$, the bioavailability of $\mathrm{Fe}$ from different types of milk (CM, cereal milk and soya-based beverage) with different contents of $\mathrm{Ca}$ and vitamins was evaluated and showed that the bioavailability of $\mathrm{Fe}$ is significantly higher in soya-based beverage compared with CM. In the present study, animals fed soya beverage without FOS (SB) had lower apparent Fe absorption and higher $\mathrm{Hb}$ and $\mathrm{Ht}$ concentrations than the animals fed cows' milk without FOS (CM).

The $\mathrm{Hb}$ and $\mathrm{Ht}$ concentrations after the $7 \mathrm{~d}$ of prebiotic ingestion presented higher $\mathrm{Hb}$ recovery in the groups that received cows' milk and soya beverage (CMF and SBF). These results are in agreement with the literature, showing that prebiotics can be effective in the regeneration of $\mathrm{Hb}$ mass ${ }^{(17,42,43)}$. The evaluation of Fe absorption by apparent absorption and hepatic Fe content did not confirm the results obtained for $\mathrm{Hb}$ and $\mathrm{Ht}$ concentrations.

Malabsorption of Fe leads to anaemia, as indicated by the reductions in $\mathrm{Hb}$ and $\mathrm{Ht}$ concentrations. In this sense, as observed previously ${ }^{(29)}$, the decreased $\mathrm{Fe}$ absorption was impacted by the use of CM. CM has low bioavailability and Fe density and excess protein and minerals, particularly $\mathrm{Ca}$, and is associated with intestinal microhaemorrhages, particularly in human infants, interfering with the absorption of Fe from other foods. In addition, it has low vitamin $\mathrm{C}$ content, considered to be an incentive factor for Fe absorption, and a high phosphorus content, a factor that reduces Fe absorption ${ }^{(44)}$. In the present study, the occult blood tests were negative in all groups of all animals. Thus, these factors could contribute to the lower concentrations of $\mathrm{Hb}$ and $\mathrm{Ht}$ in the control (CM and CMF) groups.

There are no excretory mechanisms for Fe: the absorption of Fe by the small intestine is regulated according to the needs of the body. Thus, in anaemia, an adaptive mechanism occurs, in which the Fe absorption regulating gene expression increases in both the duodenum and the caecum and $\operatorname{colon}^{(45,46)}$ to increase Fe absorption. Genes involved in Fe metabolism, such as DMT1 and ferroportin, are also expressed in the large intestine but at significantly lower levels than in the duodenum ${ }^{(47,48)}$. DMT1 transports ferrous Fe to enterocytes and macrophages. Fe can be stored as ferritin or transferred through the basolateral membrane into the plasma by ferroportin ${ }^{(49)}$. Ferroportin is found in the basolateral membrane where Fe efflux permeates ${ }^{(50)}$. The importance and function of these genes in the large intestine are still not clearly understood ${ }^{(45)}$. Studies show increased protein expression of DMT1 and ferroportin in anaemic animals that received prebiotic ${ }^{(13,22,23,51)}$

This study showed that the control animals (CM and CMF) presented higher apparent $\mathrm{Fe}$ absorption in relation to the animals that received SB with and without FOS (SB and SBF). It can be speculated that this finding is dependent on the lower concentrations of $\mathrm{Hb}$ in the control (CM and $\mathrm{CMF}$ ) groups because in Fe-deficiency anaemia, mechanisms are activated to increase Fe absorption ${ }^{(45,46)}$

The present study also showed that the FOS added in the SBF significantly increased DMT1 protein expression in the duodenum, with an increase of $173 \%$ when compared with the group that received SB and a $208 \%$ increase when compared with the group that received $\mathrm{CMF}$, in line with other studies ${ }^{(13,51)}$ that observed increased gene expression of DMT1 in the duodenum with ingestion of prebiotics in anaemic pigs. This result shows that there was greater uptake of $\mathrm{Fe}$ into the tissue observed in the SBF. This effect could have contributed to some results, considering that FOS supplementation in the group receiving soya beverage (SBF) resulted in a significant increase in the $\mathrm{Hb}$ and $\mathrm{Ht}$ concentrations in relation to the group fed with soya beverage only (SB). In addition, animals receiving FOS in soya beverage (SBF) showed higher concentrations of $\mathrm{Hb}$ and $\mathrm{Ht}$ than animals receiving CMF.

The increase in duodenal expression of DMT1 in the SBF group was surprisingly associated with lower Fe absorption. Thus, other factors such as the expression of Dcyt-b, hephaestin, haeme Fe-bearing protein in addition to the transferrin receptor, hepcidin and ferritin could be altered and explain the lower Fe absorption in this group. Unfortunately, in this project it was not possible to determine the protein expression of all these factors, and hence should be explored in future studies. The study also showed that the CM group induced anaemia, presented greater apparent $\mathrm{Fe}$ absorption and the addition of FOS in this group showed a significant increase in $\mathrm{Hb}$ and $\mathrm{Ht}$ (CMF) concentration. No alterations of DMT1 were observed in the caecum and colon and ferroportin in the intestinal segments in some experimental group. Thus, it may be speculated that the protein expression of the $\mathrm{Fe}$ absorption factors mentioned above could be increased. 
Prebiotics differ in their degree of polymerisation, and structural differences in prebiotics can affect $\mathrm{Ca}$ and Fe homeostasis and generate different physiological responses. In this study, the FOS used had a degree of polymerisation between 2 and 8 , being degraded more rapidly, with effects in proximal regions of the large intestine ${ }^{(52)}$. Thus, the magnitude of the effect on trace element absorption is affected by the type and dose of fructan ${ }^{(53)}$. Thus, it can be speculated that because of the FOS concentrations used, positive effects of FOS on $\mathrm{Ca}$ bioavailability, apparent Fe absorption and hepatic Fe content were not observed in the present study.

It can be speculated that the greater stimulus to Ca absorption could inhibit Fe absorption because studies clearly show an antagonistic relationship between $\mathrm{Ca}$ and dietary $\mathrm{Fe}^{(54)}$.

In general, studies with different types, combinations and concentrations of prebiotics did not observe any negative effect on the absorption of $\mathrm{Ca}$ and $\mathrm{Fe}$. In contrast to previous evidence, FOS increased levels of $\mathrm{Hb}$ and $\mathrm{Ht}$ and DMT1 protein expression in the duodenum or, at least, did not limit the absorption of $\mathrm{Ca}$ and $\mathrm{Fe}$.

Finally, it should be noted that there are no studies similar to the present study that prevents the direct comparison of the results. Another limitation relates to the difficulties of extrapolating the results obtained to humans. However, the importance of experimental models with animals cannot be disregarded, particularly in situations in which experiments involving humans cannot be designed to evaluate the repercussions of a food provided over periods of several days instead of in a single meal test.

\section{Acknowledgements}

The authors thank the staff of the Physiology of Nutrition Discipline wing of the Department of Physiology, Federal University of São Paulo.

The present study was supported by the National Council of Technological and Scientific Development - CNPq, Brazil (2015/CEUA no. 3498100315). The funder had no role in the design and analysis of the study or in the writing of this article.

The authorship of this manuscript received the following contributions: M. d. L. C. S., P. d. G. L. S., L. M. O. and M. B. d. M. contributed to project design, data analysis, statistical analysis, final review, manuscript presentation and critical review of the manuscript for important intellectual content; M. d. L. C. S. conducted animal experiments; M. d. L. C. S. and L. M. O. performed laboratory tests.

The authors declare that there are no conflicts of interest.

\section{References}

1. Fenollosa T \& Dalmau J (2001) Fórmulas de soja (Soya formulas). Acta Pediatr Esp 59, 85-87.

2. Food and Agricultural Organization (1992) Soymilk and related products. In FAO Agricultural Services Bulletin no. 97. Technology of production of edible flours and protein products from soybeans. Rome: FAO.

3. Rosenthal A, Deliza R, Cabral LC, et al. (2003) Effect of enzymatic treatment and filtration on sensory characteristics and physical stability of soymilk. Food Control Journal 14 , 187-192.

4. Behrens JH \& da Silva MAAP (2004) Atitude do consumidor em relação à soja e produtos derivados. Ciênc Tecnol Alim 24, 431-439

5. Cortez APB, Medeiros LCS, Speridião PGL, et al. (2007) Conhecimento de pediatras e nutricionistas sobre o tratamento da alergia ao leite de vaca no lactente (Training of paediatricians and nutritionists on the treatment of allergy to cow's milk in the infant). Rev Paul Pediatr 25, 106-113.

6. Faria DPB, Cortez APB, Speridião PGL, et al. (2017) Conhecimento e prática de pediatras e nutricionistas sobre o tratamento da alergia às proteínas do leite de vaca no lactente (Knowledge and practice of paediatricians and nutritionists on the treatment of allergy to cow's milk proteins in infants). Thesis, Federal University of São Paulo.

7. Osman MA, Reid PM \& Weber CW (2002) Thermal inactivation of tepary bean (Phaseolus acutifolius), soybean and lima bean protease inhibitors: effect of acidic and basic pH. Food Chem 78, 419-423.

8. Bajpai S, Aparna Sharma A \& Gupta MN (2005) Removal and recovery of antinutritional factors from soybean flour. Food Chem 89, 497-501.

9. Sandberg AS \& Andlid T (2002) Phytogenic and microbial phytase in human nutrition. Int J Food Sci and Tech 37, 823-833.

10. Lopez HW, Leenhardt F, Coudray C, et al. (2002) Minerals and phytic acid interactions: is it a real problem for human nutrition? Int J Food Sci and Tech 37, 727-739.

11. Pereira GAP, Genaro PS, Pinheiro MM, et al. (2009) Cálcio dietético - estratégias para otimizar o consumo (Dietary calcium - strategies to optimise consumption). Rev Bras Reumatol 49, 164-180.

12. Worldwide Prevalence of Anaemia 1993-2005 (2008) WHO Global Database on Anaemia. http://apps.who.int/iris/bitstream/10665/43894/1/9789241596657_eng.pdf （accessed January 2015).

13. Tako E, Glahn RP, Welch RM, et al. (2008) Dietary inulin affects the expression of intestinal enterocyte iron transporters, receptors and storage protein and alters the microbiota in the pig intestine. Br J Nutr 99, 472-480.

14. Yasuda K, Roneker KR, Miller DD, et al. (2006) Supplemental dietary inulin affects the bioavailability of iron in corn and soybean meal to young pigs. J Nutr 136, 3033-3038.

15. Pitarresi G, Tripodo G, Cavallaro G, et al. (2007) Inulin-iron complexes: a potential treatment of iron deficiency anaemia. Eur J Pharm Biopharm 68, 267-276.

16. Lobo AR, Colli C \& Filisetti TMCC (2006) Fructooligosaccharides improve bone mass and biomechanical properties in rats. Nutr Res 26, 413-420.

17. Freitas KC, Amâncio OM \& de Morais MB (2012) Highperformance inulin and oligofructose prebiotics increase the intestinal absorption of iron in rats with iron deficiency anaemia during the growth phase. BrJ Nutr 108, 1008-1016.

18. Tako E \& Glahn RP (2012) Intra-amniotic administration and dietary inulin affect the iron status and intestinal functionality of iron-deficient broiler chickens. Poult Sci 91, 1361-1370.

19. Tako E, Glahn RP, Knez M, et al. (2014) The effect of wheat prebiotics on the gut bacterial population and iron status of iron deficient broiler chickens. Nutr J 13, 58 .

20. Mugambi MN, Musekiwa A, Lombard M, et al. (2012) Synbiotics, probiotics or prebiotics in infant formula for full term infants: a systematic review. Nutr J 11, 81.

21. Freitas KC, Amancio OMS, Novo NF, et al. (2006) Partially hydrolyzed guar gum increases intestinal absorption of iron in growing rats with iron deficiency anemia. Clin Nutr 25, 851-858. 
22. Marciano R, Santamarina AB, de Santana AA, et al. (2015) Effects of prebiotic supplementation on the expression of proteins regulating iron absorption in anaemic growing rats. Br J Nutr 113, 901-908.

23. Carvalho L, Brait D, Vaz M, et al. (2017) Partially hydrolyzed guar gum increases ferroportin expression in the colon of anemic growing rats. Nutrients $\mathbf{9}, 228-238$.

24. Bosscher D, Dyck KV, Robberecht H, et al. (1998) Bioavailability of calcium and zinc from cow's milk-based versus soyabased infant food. Int J Food Sc Nutr 49, 277-283.

25. Heaney RP, Dowell MS, Rafferty K, et al. (2000) Bioavailability of the calcium in fortified soy imitation milk, with some observations on method. Am J Clin Nutr 71, 1166-1169.

26. Zhao Y, Martin BR \& Weaver CM (2005) Calcium bioavailability of calcium carbonate fortified soymilk is equivalent to cow's milk in young women. J Nutr 135, 2379-2382.

27. Tang AL, Walker KZ, Wilcox G, et al. (2010) Calcium absorption in Australian osteopenic post-menopausal women: an acute comparative study of fortified soymilk to cows' milk. Asia Pac J Clin Nutr 19, 243-249.

28. Promchan J \& Shiowatana J (2005) A dynamic continuousflow dialysis system with on-line electrothermal atomicabsorption spectrometric and $\mathrm{pH}$ measurements for in-vitro determination of iron bioavailability by simulated gastrointestinal digestion. Anal Bioanal Chem 382, 1360-1367.

29. Costa ML, Freitas KC, Amâncio OM, et al. (2009) Iron absorption from infant formula and iron-fortified cow's milk: experimental model in weanling rats. $J$ Pediatr (Rio J) $\mathbf{8 5}$, 449-454.

30. Farjalla LB (2017) Absorção intestinal do ferro de fórmulas infantis anti-regurgitação espessadas com fibra alimentar goma jataí e amido de milho em ratos recém-desmamados (Intestinal iron absorption of anti-regurgitation infant formulas thickened with dietary fibre jataí gum and corn starch in newly weaned rats). Thesis, Federal University of São Paulo.

31. Brazilian National Health Surveillance Agency (2011) Resolution RDC no. 43 of September 19 provides for the "Technical Regulation for infant formulas for infants". http://www.saude. rj.gov.br/comum/code/MostrarArquivo.php?C=MTk4MQ\%2C \%2C (accessed September 2016).

32. Marks GE, Moore CE, Kanabrocki EL, et al. (1971) Determination of trace elements in human tissue. I, Cd, Fe, $\mathrm{Zn}, \mathrm{Mg}$ and Ca. Appl Spectrosc 26, 523-527.

33. Sarriá B, López-Fandiño R \& Vaquero MP (2001) Does processing of a powder or in-bottle-sterilized liquid infant formula affect calcium bioavailability? Nutrition 17, 326-331.

34. Sarriá B \& Vaquero MP (2004) Iron bioavailability from powered and in-bottle-sterilized infant formulas in suckling and weanling rats. Nutrition 20, 788-793.

35. Fernandez FJ \& Kahn HL (1971) Clinical methods for atomic absorption spectroscopy. Clin Chem Newsl 3, 24.

36. Wintrobe M, Mollin D, Herbert V, et al. (1968) Anemias nutricionales. Org Mund Salud Ser Inf Técn 405, 5-39.

37. Silva ML, Speridião PG, Marciano R, et al. (2015) Effects of soy beverage and soy-based formula on growth, weight, and fecal moisture: Experimental study in rats. J Pediatr 91, 306-312.
38. Silva ML, Speridião PG, Marciano R, et al. (2017) Intestinal absorption of iron and calcium from soy and cow's milk-based infant formulas in weanling rats pups. Rev Nutr 30, 13-22.

39. Liener IE (1994) Implications of antinutritional components in soybean foods. Crit Rev Food Sci Nutr 34, 31-67.

40. Lopes LA (1999) Efeitos da restrição de macronutrientes sobre o crescimento corporal e a histopatologia do sistema nervoso central de ratos jovens desnutridos intra-útero (Effects of macronutrient restriction on body growth and central nervous system histopathology of intrauterine undernourished young rats). Thesis, Federal University of São Paulo.

41. Heaney RP (2001) Factors influencing the measurement of bioavailability, taking calcium as a model. J Nutr 131, 1344S-1348S

42. Ohta A, Ohtsuki M, Baba S, et al. (1995) Effects of fructooligosaccharides on the absorption of iron, calcium and magnesium in iron-deficient anemic rats. J Nutr Sci Vitaminol 41, 281-291.

43. dos Santos EF, Tsuboi KH, Araújo MR, et al. (2011) A ingestão de prébioticos previne a malabsorção de ferro e anemia induzidas pela gastrectomia?: Estudo experimental em ratos (Intake of prebiotics prevents iron malabsorption and anemia induced by gastrectomy?: Experimental study in rats). Arq Bras Cir Dig 24, 9-14.

44. Oliveira MA \& Osório MM (2005) Consumo de leite de vaca e anemia ferropriva na infância. J Pediatr (Rio J) 81, 361-367.

45. Takeuchi K, Bjarnason I, Laftah AH, et al. (2005) Expression of iron absorption genes in mouse large intestine. Scand J Gastroenterol 40, 169-177.

46. Johnston KL, Johnson DM, Marks J, et al. (2006) Non-haem iron transport in the rat proximal colon. Eur J Clin Invest 36, $35-40$.

47. Wang J \& Pantopoulos K (2011) Regulation of cellular iron metabolism. Biochem J 434, 365-381.

48. World Health Organization (2004) International Micronutrient Malnutrition Prevention and Control Program, Centers for Disease Control and Prevention. Division of Nutrition and Physical Activity. Assessing the iron status of populations: including literature reviews, 2nd ed. Geneva: WHO.

49. Frazer DM, Wilkins SJ, Becker EM, et al. (2002) Hepcidin expression inversely correlates with the expression of duodenal iron transporters and iron absorption in rats. Gastroenterology 123, 835-844.

50. Ganz T (2011) Hepcidin and iron regulation, 10 years later. Blood 117, 4425-4433.

51. Yasuda K, Dawson HD, Wasmuth EV, et al. (2009) Supplemental dietary inulin influences expression of iron and inflammation related genes in young pigs. J Nutr 139, 2018-2023.

52. Roberfroid MB (1998) Prebiotics and symbiotics: concepts and nutritional properties. Br J Nutr 80, S197-S202.

53. Scholz-Ahrens KE \& Schrezenmeir J (2007) Inulin and oligofructose and mineral metabolism: the evidence from animal trials. J Nutr 137, 2513S-2523S.

54. Hallberg L, Brune M, Erlandsson M, et al. (1991) Calcium: effect of different amounts on nonheme-and heme-iron absorption in humans. Am J Clin Nutr 53, 112-119. 